\title{
Factors Affecting the Deployment of Learning Analytics in Developing Countries: Case of Egypt
}

\author{
https://doi.org/10.3991/ijet.v17i03.24405 \\ Mai Mahmoud ${ }^{1,2(\bowtie)}$, Georgios Dafoulas ${ }^{2}$, Rasha Abd ElAziz ${ }^{1}$, Noha Saleeb ${ }^{2}$ \\ ${ }^{1}$ Arab Academy for Science, Technology and Martime Transport, Alexandria, Egypt \\ ${ }^{2}$ Middlesex University, London, UK \\ mmmorsyeaast.edu, mm3163@live.mdx.ac.uk
}

\begin{abstract}
The higher education institutions in developing countries such as Egypt are challenged with the high enrollment student rates, crowded classes and inability to track the progress of each student individually which increased the demand to find a solution that can redeem those problems. Although the usage of learning analytics is an expanding solution to support different educational challenges from performance tracking to detecting students at risks, learning analytics' developments concentrated on addressing solutions for developed countries. Accordingly, the discipline still requires a broader and indepth interpretation of its contextual usage in developing countries especially Egypt. A research model has been constructed based on literature and tested for its validity and reliability. A questionnaire has been distributed on 148 university students. The study used smart-PLS to interpret and analyze the collected data. The study revealed that organizational culture, data accessibility, trustworthy, visualization has a positive effect on the awareness, while lack of ability has a negative effect on the awareness. Both infrastructure and awareness have significant positive effect on learning analytics impact. The research indicates high learning analytics awareness and high perceived impact on the Egyptian higher education. Evidence should be provided with the collection of more insights from students, faculty members and decision makers.
\end{abstract}

Keywords-learning analytics, deployment factors, students, developing countries

\section{Introduction}

The higher education sector globally has been transforming over the past years with the technological advancements introduced to the field, it has changed the way the learning process is being viewed. Online learning and blended learning have emerged resulting in a vast amount of students' data and a needing call for a tool that could help at extracting meaningful information helping at monitoring the overall educational process, one of these tools is learning analytics which was introduced at the beginning of year 2011 [1,2,3]. On the contrary, universities in developing countries especially in the Arab region are falling behind in the race of educational digital transformation which was exposed during different crisis such as the Arab Spring 
revolutions and the COVID-19. The Arab region consists of 22 countries with a population of more than 407 million, 20\% of which exists in Egypt [4].

The technological capabilities of the higher education sector in Egypt have been challenged in 2020 with the appearance of the Coronavirus and its consequences. Different educational institutions have been encouraged to shift their learning activities online through learning management systems, video conferencing software and social media.

The online operation of education does not only mean delivery of lectures but also finding a way for remotely tracking the student's performance and assessment due to large number of students enrolled; as Egypt has always suffered from high enrollment rates and crowded classes [5].

While learning analytics potential is being recognized in the developed nations such as Australia, America and Canada [6], research, data about its utilization, and factors that affect its deployment is rare in developing countries in general, and Egypt in particular.

\section{Literature review}

\subsection{Learning analytics origin and definition}

Learning analytics is a tool needed to monitor the learning environment usage and the learning itself [7] and can help students to have a clear picture about their performance throughout the course work and gives the lecturer a comprehensive view about the student's behavior toward the course content.

According to [8] Learning analytics is the process of interpreting different data ranges produced by the students' actions within the educational information system such as assignments, exams, online activities and discussion forums, in order to evaluate academic achievements, performance prediction and detect potential risks.

[9] has agreed that learning analytics is the data usage to create statistical analysis and predictive models to gain a better understandings and work on complicated issues. Same as [10] who described learning analytics as the field of gathering and analyzing data obtained from online interaction with the educational resources with different aims such as patterns discovery in the learning process and detection of student performance trends or obstacles.

The learning analytics had a varied range of definitions throughout the past years that could be summarized as the use of the data generated by learners to discover meaningful information and create beneficial interventions through the analysis of the learning process, learning management records, learning resources and activities in order to improve the creation of performance predictive models, generate recommendations and educational process improvement. 


\subsection{Learning analytics benefits and challenges}

There are many benefits that have strengthened institutions' interest in Learning Analytics, which has become one of the most prominent optimal solutions to educational problems and improved performance, as stated by [11] given its ability to provide an opportunity for instructors to quickly identify patterns of user behavior and learn about the nature of student development stages, in addition to its ability to provide instant collection, measuring and analyzing learners data and their contexts with the aim of understanding the learning process and the environments in which learning takes place. According to [12] Learning analytics is a kind of smart use of data resulted at improved accountability at all levels. [13], [14], [15] have articulated many learning analytics benefits which are target courses identification, improvement of curriculum, learning personalization, student's performance prediction, retention rate advancement, feedback and recommendations and instructor performance enhancement. [16] has categorized the benefits according to the learning analytics stakeholders classified into learners, teachers, institutions, researchers, course designers and parents: Learners' benefits such as student engagement enhancement, learning outcomes improvement, personalization, Teachers' benefits such as efficient interventions, teaching strategy improvement and activity monitoring. Institutions' benefits such as cost efficiency and evidence based decisions.

However, despite the many benefits of learning analytics, there are many challenges as well. For example, learning platforms are unable to accurately capture learning experiences [17]. Another challenge is finding the relationship between data patterns and learners' behavior [18]. In addition, data privacy management and ethics is also a major concern [19], [20], [21].

The bottom line is that Learning Analytics provide great opportunities for organizations working in higher education. Given the influence of advanced technologies on learning, there is a wide range of new possibilities that could be achieved putting in mind the challenges that could be faced.

In order to make the best out of learning analytics the benefits of learning analytics should be mapped to stakeholders' expected benefits in a try to propose learning analytics solutions that matches the required purpose to accelerate its deployment.

\subsection{Learning analytics frameworks}

[22] examined the Learning analytics readiness instrument to help educational institutions determine the strengths and weaknesses with regard to the following factors; Governance and Infrastructure, Ability, Data, Culture and Process. The study has found that the way the institution deals with the various data types and its collection and how it is being stored and maintained (data) and the institution is capable and willing to invest in learning analytics with the presence of professional stuff that has the skills and experiences in fields related to the data management, training and documentation (Governance and Infrastructure) are rated higher than the professional stuff that has the skills and experiences in issues related to the implementation of learning analytics (Ability), the institutional norms concerning data utilization to 
generate reports and help in the decision making process in addition to data usage and security (culture) with the presence of institutional resources and acceptance. Upon this study [23] modified the proposed LARI (learning analytics readiness instrument) to test five factors: Culture; Data Management Expertise; Data Analysis Expertise; Communication and Policy Application; and Training. The study conducted the survey in Twenty-four institutions and 560 respondents participated.

[24] proposed the Evaluation Framework for Learning Analytics (EFLA) that test the effectiveness of the learning analytics tool according to 3 different aspects which are the data being used and how is being utilized, the awareness and reflection of the importance of learning analytics and the impact of the learning analytics on two main stakeholders: students and teachers.

Researchers have concentrated on aspects such as ethics, policy creation for learning analytics implementation in educational institutions in European and western cultures with a negligible focus on developing countries especially the Arabian region.

\subsection{Hypotheses development}

Literature has focused on to the creation of policy frameworks to implement learning analytics already implemented at scale. There is rare presence for studies that examines the factors that affect the learning analytics deployment except for [22], [23] and [24], the first two authors have discussed the institutional learning analytics readiness and the latent author has proposed an evaluation tool of the effectiveness of learning analytics systems. The research has used this three researches as a base for its study as shown in Figure 1.

\section{- Organizational culture (OC)}

Organizational culture is recognized as a significant factor influencing technological innovation acceptance and awareness [25]; it may either accelerate or delay its maintenance and implementation. It refers to the presence of an institutional culture that encourages the usage and implementation of new ideas, as well as the existence of defined procedures and rules [22], [23].

H1. Organizational culture has a positive effect on Learning analytics awareness.

\section{- University Ability (UA)}

Appropriate set of skills is required for the successful deployment of learning analytics. It refers to the availability of resources and technological abilities [26]. The availability of resources to use LA, as well as the necessary abilities to apply LA, backed up by the necessary training [27]. This component is critical for spreading awareness inside the educational institution because it helps at improving the necessary skills and resources for learning analytics maintenance and implementation [22].

H2. University Ability has a positive effect on learning analytics awareness. 


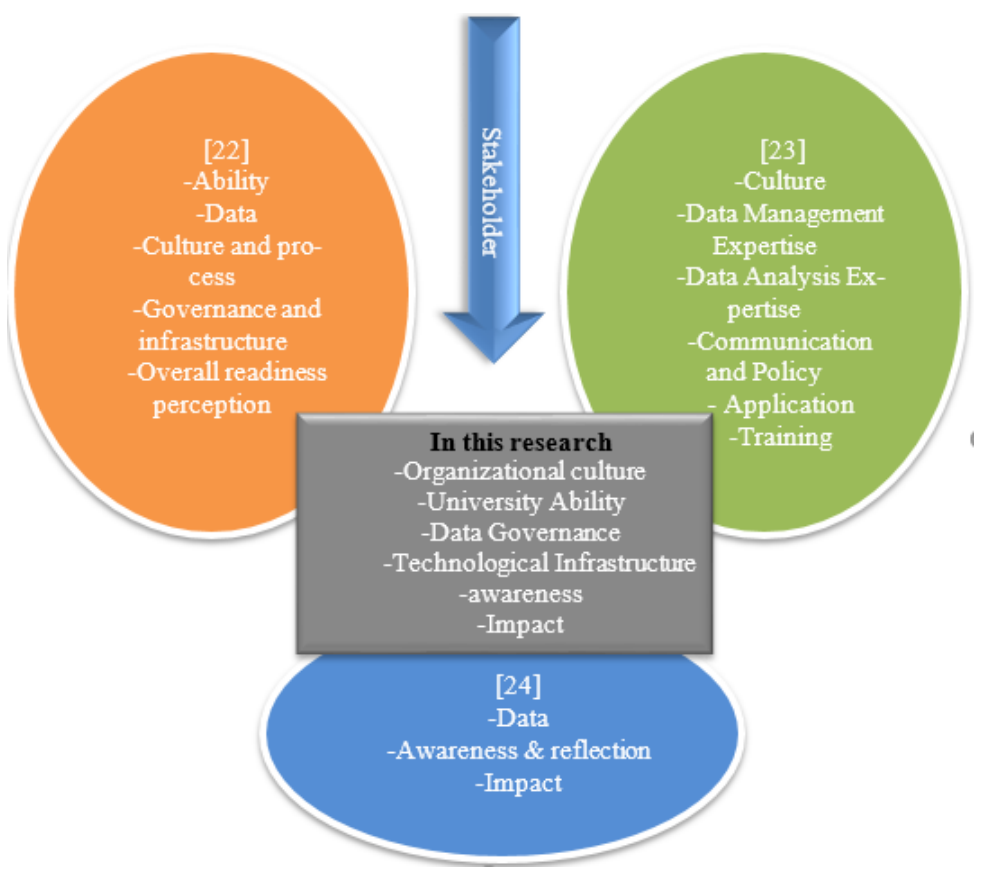

Fig. 1. Research positioning

\section{- Data Governance (DG)}

Data governance is identified as a vital component in the development of successful learning analytics [28]. It refers to the availability of accurate data in a timely manner with self-descriptive visualizations, accessible without any constraints while taking both privacy and data ethical usage into account [29], [30]. Data is recognized by stakeholders as a crucial aspect for learning analytics maintenance and awareness [22], [24].

H3. Data governance has a positive effect on learning analytics awareness.

\section{- Technological Infrastructure (TI)}

Technological Infrastructure is being highlighted as one of the most important aspects influencing the impact of learning analytics on stakeholders and educational institutions. It refers to the existence of technological infrastructure at the educational institution that can support the implementation of learning analytics [22], [31]. Developing countries in general and Egypt in particular have been aiming at the recent years to maintain effective technological infrastructure to operate e-learning services through learning management systems [32]; The existence of technological infrastructure that is compatible with learning analytics specifications can lead to smooth integration of data with good operational practices can effect positively on the learning analytics impact [33], [34].

H4. Technological Infrastructure has a positive effect on learning analytics impact. 


\section{- Learning analytics awareness (LAW) and Learning analytics impact (LAI)}

The technological awareness can enhance the impact and use of technology products or service [35]. It refers to the level of understanding of learning analytics among stakeholders and the realization of the advantages and usage of learning analytics [28], [24]. Although raising awareness is vital for increasing technology adoption, it is sometimes overlooked as a component in adoption [36], [37]. It is suggested that individuals with high technology awareness may perceive technological impact positively [38]. Learning analytics impact in this research is defined as the perceived impact of learning analytics on stakeholders' individual advantages as well as the educational institution's overall advantage [39], [24].

H5. Learning analytics awareness has a positive effect on learning analytics impact.

\section{$3 \quad$ Methodology}

This study used 6 measurement variable each have different items which measured with 5-point Likert scales. Table 1 describes number of items used for each construct and the possible source from where each construct was collected. The research tries to keep all the items of each construct to exemplify their nature and directions. All the items of each construct and their corresponding loading are presented in appendix A.

Table 1. Measurement variables

\begin{tabular}{|l|c|c|c|}
\hline \multicolumn{1}{|c|}{ Construct } & Name & Included/Total items & Source \\
\hline Q12 & Organizational Culture (OC) & $9 / 10$ & {$[22],[23],[25]$} \\
\hline Q13 & University Ability (UA) & $3 / 5$ & {$[22],[26],[27]$} \\
\hline Q14 & Data Governance (DG) & $5 / 6$ & {$[22],[24],[29],[28],[30]$} \\
\hline Q15 & Technological Infrastructure (TI) & $3 / 3$ & {$[22],[31]$} \\
\hline Q16 & Learning Analytics Awareness (LAW) & $5 / 5$ & {$[24],[28],[36],[37]$} \\
\hline Q17 & Learning Analytics impact (LAI) & $7 / 8$ & {$[24],[39]$} \\
\hline
\end{tabular}

\subsection{Sampling and data collection}

The research followed random stratified sampling technique, As the target population consists of undergraduate students who must be using learning management systems in conducting their online learning activities in the Egyptian universities [40] A total of 148 students have completed and returned the questionnaire. The questionnaire was hosted on Qualtrics survey platform. The data collected is analyzed using Smart-PLS version 3.2.2.

The demographic details of the respondents are summarized in the Table 2, which shows that males and females were fairly equal. The average age of respondents is 20 with standard deviation (SD) 1.46. The respondent ages at different study year are fairly consistent, the average age of respondents from first year to fifth year is 18 (SD, $0.78), 19$ (SD, 0.91), 20 (SD, 1.16), 21 (SD, 1.05) and 22 (SD, 1.03) respectively, 
however, the age distribution is wide with respondents in all the study year except fifth year. The study discipline business administration and engineering is more represented in the data than other discipline.

Table 2. Demographic information of the respondents: gender, age, study year and study discipline of the respondent data

\begin{tabular}{|c|c|c|c|c|c|c|c|c|}
\hline & Frequency & Percent & Mean & Median & SD & & Frequency & Percent \\
\hline \multicolumn{6}{|l|}{ Gender } & \multicolumn{3}{|l|}{ College type } \\
\hline Female & 76 & 51 & & & & Engineering & 50 & 34 \\
\hline \multirow[t]{2}{*}{ Male } & 72 & 49 & & & & Computer science & 1 & 1 \\
\hline & & & & & & Logistics & 1 & 1 \\
\hline Age & & & 20.2 & 20 & 1.46 & Business administration & 82 & 55 \\
\hline 20 or less & 83 & 56 & & & & Dentistry & 3 & 2 \\
\hline \multirow[t]{2}{*}{ Above 20} & 65 & 44 & & & & Pharmaceutical & 5 & 3 \\
\hline & & & & & & Medicine & 2 & 1 \\
\hline \multicolumn{6}{|c|}{ Study year and age distribution ${ }^{a}$} & Media & 4 & 3 \\
\hline First & 29 & 20 & 18.5 & 18 & 0.78 & & & \\
\hline Second & 36 & 24 & 19.5 & 19 & 0.91 & & & \\
\hline Third & 35 & 24 & 20.7 & 20 & 1.16 & & & \\
\hline Fourth & 42 & 28 & 21.1 & 21 & 1.05 & & & \\
\hline Fifth & 6 & 4 & 22.3 & 22 & 1.03 & & & \\
\hline
\end{tabular}

$\mathrm{SD}=$ Standard deviation, $\mathrm{a}=$ Summary statistics (mean, median and SD) of student age at different study year

\section{$4 \quad$ Results and findings}

\subsection{Measurement model}

Validity and reliability. A conceptual model was articulated for assessing the effect of learning analytics readiness factors on the stakeholders' awareness which affect the perceived impact of learning analytics in developing countries, afterwards the Partial Least Square Structural Equation Modeling (PLS-SEM) was used to examine the conceptual model. The conceptual model evaluation and the analysis were conducted via component-based PLS-SEM in SmartPLS 3 [41]. SmartPLS is referred to as the PLS approach to Structural Equation Modeling (SEM). PLS-SEM illustrated the causal relationships and complex structure of associations among variables which generally difficult to uncover using naïve model. Its handle the data to estimate the significance value of path coefficient. Indeed, PLS-SEM does not rest on any distributional assumptions but there is another community co-variance-based structural equation methods (CB-SEM) which rely on distribution assumption. The CB-SEM more suitable for model selection for the data whereas PLS-SEM is better suited for prediction-oriented studies [42], [43]. Although, PLS-PM is a non- parametric approach, the 
study uses bootstrapping to obtain information about the variability of the parameter estimates.

The present study aimed to apply PLS-SEM to better understand the impact of learning analytics on students and associated influencing factors [44], [45]. The proposed conceptual model is investigated in two different phases, the models constructed the latent variables and examined the associations between latent indicators and their manifest variables at the first phase, and the second phase a structural model was developed for the study of the relationships between the latent indicators. The conceptual model elucidated the associations between the latent variables and their associated manifest variables.

Since there are no missing data points in the dataset. So, imputation isn't required for subsequently analysis. To assess convergent validity average variance extracted (AVE), Composite Reliability (CR), Cronbach's alpha (Alpha) and DillonGoldstein's rho were reported (see Table 3). AVE measures the amount of variance that a construct captures from its items in relation to the amount of variance due to measurement error. The value of $\mathrm{CR}$ represents the degree to which the construct indicators indicate the latent construct. If the items of a construct are unidirectional, they have to highly correlated, and Cronbach's alpha (Alpha) measure intra variable correlation between items. Dillon-Goldstein's rho which focuses on the variance of the sum of items in the contract. The standard threshold values for the Cronbach's alpha (Alpha) and Goldstein's rho is greater than 0.7 [46], CR greater than 0.7 [47], and for AVE is greater than 0.5 [48], [47]. The resulting metric mostly exceed the threshold then the convergent validity was confirmed for this study model.

Table 3. Convergent and discriminant validity

\begin{tabular}{|l|c|c|c|c|c|c|c|c|c|c|}
\hline & AVE & CR & Alpha & Rho & OC & UA & D & INF & LAW & LAI \\
\hline OC & 0.513 & 0.904 & 0.890 & 0.926 & $\mathbf{0 . 7 1 6}$ & & & & & \\
\hline UA & 0.701 & 0.875 & 0.788 & 0.826 & 0.701 & $\mathbf{0 . 8 3 7}$ & & & & \\
\hline DG & 0.610 & 0.887 & 0.841 & 0.851 & 0.546 & 0.656 & $\mathbf{0 . 7 8 1}$ & & & \\
\hline TI & 0.738 & 0.894 & 0.823 & 0.846 & 0.590 & 0.726 & 0.701 & $\mathbf{0 . 8 5 9}$ & & \\
\hline LAW & 0.697 & 0.920 & 0.891 & 0.895 & 0.343 & 0.203 & 0.367 & 0.343 & $\mathbf{0 . 8 3 5}$ & \\
\hline LAI & 0.607 & 0.915 & 0.892 & 0.893 & 0.418 & 0.294 & 0.371 & 0.375 & 0.698 & $\mathbf{0 . 7 7 9}$ \\
\hline
\end{tabular}

Square roots of AVEs are presented in bold in the diagonal.

Discriminant validity is next attempt was to evaluate the latent constructs. Basically, it describes that the manifest variable in any construct is distinct from other constructs in the path model. To assess discriminative variability, the square root of AVE of construct and the corresponding correlation between it and other construct were compared (see Table 2). For a given construct the square root of AVE should be higher than the correlation between it and others [49]. It is also assessed that no intercorrelation between construct was higher than 0.9 [50].

The Heterotrait-monotrait (HTMT) ratio generally used to assess discriminant validity. To test whether a given construct differs from other constructs, the value of HTMT should be significantly less than one [51], [52]. All the values of HTMT are less than one in Table 4; that is apparent that all variables also achieved discriminant validity following the HTMT criterion. Finally, the study determined that the loadings 
of every items with corresponding construct should be higher than the others (Appendix B). All of the measurement described earlier permits the discriminant validity and reliability of the model.

Table 4. Discriminant validity [Heterotrait-monotrait ratio (HTMT)]

\begin{tabular}{|l|c|c|c|c|c|c|}
\hline & OC & UA & DG & TI & LAW & LAI \\
\hline OC & & & & & & \\
\hline UA & 0.920 & & & & & \\
\hline DG & 0.690 & 0.816 & & & & \\
\hline TI & 0.752 & 0.904 & 0.848 & & & \\
\hline LAW & 0.308 & 0.232 & 0.409 & 0.396 & & \\
\hline LAI & 0.425 & 0.359 & 0.426 & 0.434 & 0.778 & \\
\hline
\end{tabular}

The initial requirement of a path model is that it should contains 150 observations and three or more indicators on constructs. However, some research suggest that minimum sample size of a path model is ten times the largest number of structural paths directed at a particular latent construct in the structural model or ten times of largest number of formative items of a construct [53], [54]. The study used a total of 148 observations.

\subsection{Structural model}

A resample of 5000 times bootstrapping was suggested for assessing the structural model looking for the R2, beta, and corresponding t-values [47]. They also recommended that, in addition to these basic measures, investigators should also report the effect sizes (f2). The coefficient of determination is a measure of model's predictive accuracy which determine overall effect size and variance explained in the endogenous construct for the path model. The organizational culture, university ability and the data governance accounted for $19.3 \%$ of the variance of learning analytics awareness toward the learning analytics impact (see Figure 2). Moreover, the model accounts for $50.8 \%$ of learning analytics awareness to learning analytics impact. Moreover, the inner path model was 0.508 for the learning analytics impact endogenous latent construct. This indicates that the learning analytics awareness and technological infrastructure substantially explain $50.8 \%$ of the variance in the learning analytics impact, meaning that about $50.8 \%$ of the change in the learning analytics impact was due to technological infrastructure and learning analytics awareness constructs followed by university administration and facilities (e.g., organizational culture, ability and the security of personal data) in the model. 


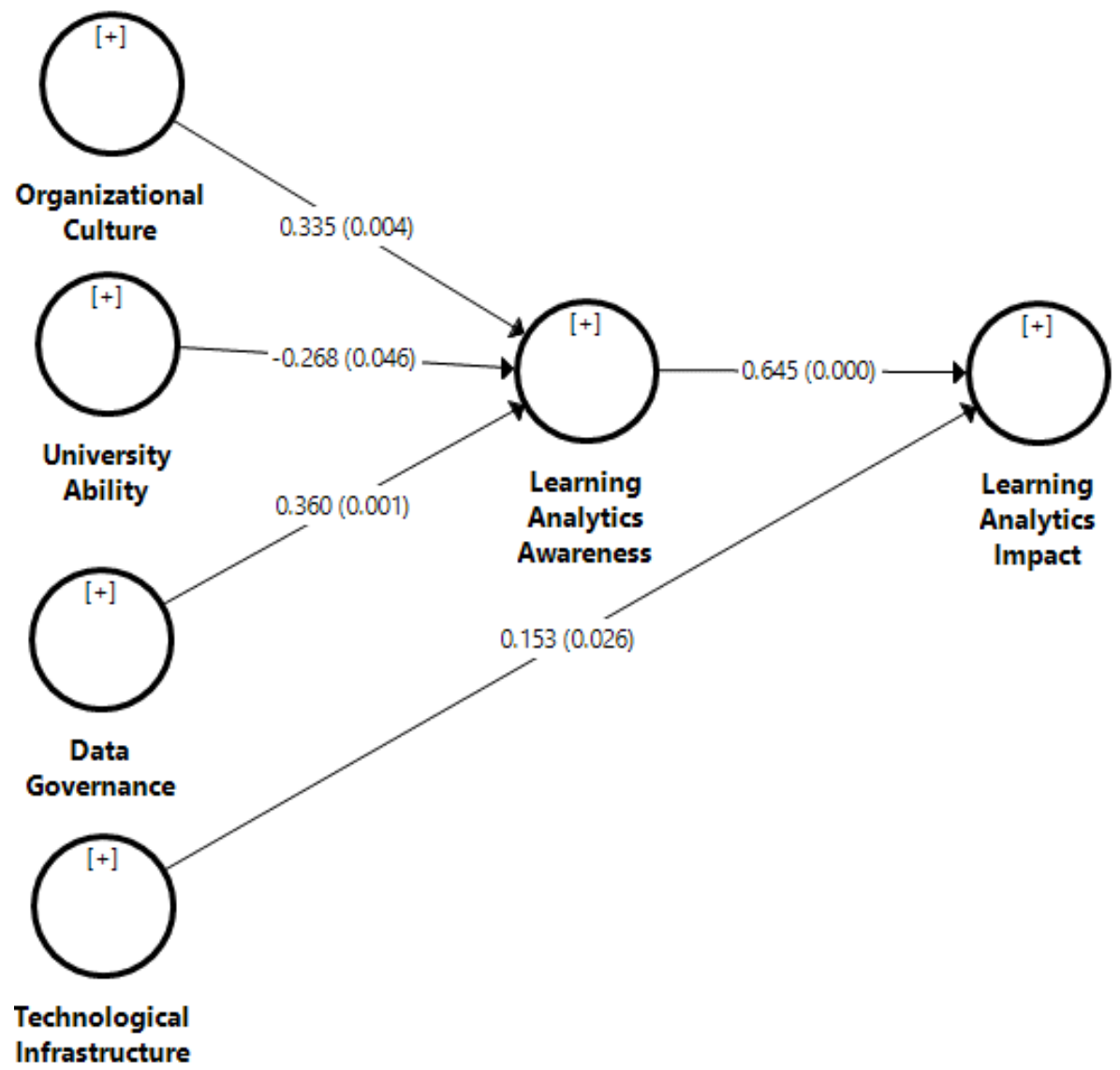

Fig. 2. Path model with direct effect (model-1)

Now, the study looked at the relationships between the variables. Organizational culture positively and significantly affected learning analytics awareness $(\beta=0.335 ; p$ $<0.01)$ and also the data governance positively and significantly affected learning analytics awareness $(\beta=0.360 ; \mathrm{p}<0.01)$. However, the university ability negatively and significantly affected learning analytics awareness $(\beta=-0.268 ; \mathrm{p}<0.05)$. The latent construct learning analytics awareness positively and significantly affected learning analytics impact $(\beta=0.645 ; \mathrm{p}<0.01)$. In addition, technological infrastructure also positively and significantly affected learning analytics impact $(\beta=0.153 ; \mathrm{p}<$ $0.05)$ Thus all the direct path in the model are positive except university ability to learning analytics awareness and statistically significant (Figure 2). Therefore, the model approve the hypothesis H1-H5 except H2 (See Table 5). 
Table 5. Confirmation of hypotheses

\begin{tabular}{|c|c|c|c|c|c|c|}
\hline H\# & IV $\rightarrow$ DV & Hypothesis & Beta & t-value & Decision & f2 \\
\hline H1 & OC $\rightarrow$ LAW & $\begin{array}{c}\text { Organizational culture have a positive effect on } \\
\text { learning analytics awareness }\end{array}$ & 0.335 & 3.125 & Supported & 0.069 \\
\hline H2 & UA $\rightarrow$ LAW & $\begin{array}{c}\text { University ability have a positive effect on } \\
\text { learning analytics awareness }\end{array}$ & -0.268 & 2.063 & Not supported & 0.036 \\
\hline H3 & DG $\rightarrow$ LAW & $\begin{array}{c}\text { Data governance have a positive effect on } \\
\text { learning analytics awareness }\end{array}$ & 0.360 & 3.260 & Supported & 0.089 \\
\hline H4 & TI $\rightarrow$ LAI & $\begin{array}{c}\text { Technological Infrastructure have a positive } \\
\text { effect on learning analytics impact }\end{array}$ & 0.153 & 2.184 & Supported & 0.042 \\
\hline H5 & $\begin{array}{c}\text { LAW } \rightarrow \\
\text { LAI }\end{array}$ & $\begin{array}{c}\text { Learning analytics awareness have a positive } \\
\text { effect on learning analytics impact }\end{array}$ & 0.645 & 9.236 & Supported & 0.746 \\
\hline
\end{tabular}

In this section, the study assessed effect sizes (f2). Basically, p-value shows significance of the associations but it does not display the size of an effect. As a result, readers have an understanding gap for interpreting the data and results. Therefore, both of the measure substantive significance (f2) and statistical significance (pvalues) must be reported. The study followed Cohen's (1988) guidelines [55], which are 0.02 for small effects, 0.15 for medium effects, and 0.35 for large effects for measuring the effect size. The study observed that the effect size for the relationship between learning analytics awareness and learning analytics impact have a large effect and all other relationships had a small effect.

The study evaluated indirect effect beside direct effects which measure the influence of one construct on another construct by taking an indirect path. A numerous number of indirect effects observed to the model, for instance, Organizational culture to learning analytics impact (Table 6).

Table 6. Direct and indirect effect of construct

\begin{tabular}{|l|c|c|}
\hline \multicolumn{1}{|c|}{ Construct Name } & $\begin{array}{c}\text { Direct effect to Learning } \\
\text { Analytics Awareness }\end{array}$ & $\begin{array}{c}\text { Indirect effect to Learning } \\
\text { Analytics Impact }\end{array}$ \\
\hline Organizational Culture & 0.335 & 0.216 \\
\hline University Ability & -0.268 & -0.173 \\
\hline Data Governance & 0.360 & 0.232 \\
\hline Technological Infrastructure & 0.153 & \\
\hline Learning Analytics Awareness & 0.645 & \\
\hline
\end{tabular}

\section{Discussion}

This study has examined a structural equation model using smart-PLS to explain the factors that affect learning analytics impact from the university students' perspective. Using this model as a foundation, the research investigated the role of university culture, data governance and university ability on the learning analytics awareness and how both awareness and technological infrastructure affects learning analytics impact. According to the findings of the study, several influencing aspects and criteria 
that may have a significant impact on learning analytics awareness and impact should be taken into account throughout the deployment and implementation of learning analytics. While testing the model, learning analytics impact on students is explained indirectly by organizational culture, ability and data availability and trustworthy and directly by the infrastructure of the university.

Findings from the structural equation modeling in which hypotheses were tested, it was seen that hypotheses $\mathrm{H} 1, \mathrm{H} 3, \mathrm{H} 4$, and $\mathrm{H} 5$ were fully confirmed except for $\mathrm{H} 2$. Therefore, we conclude that the organizational culture and the data governance have a significant and positive effect on learning analytics awareness agreeing with [22], [23], [25], [29], [30] except ability which have negative effect on learning analytics awareness. However, all the factors showed a direct and significant effect on learning analytics impact. Moreover, university Infrastructure have a positive and significant effect on learning analytics impact as it was confirmed by [22], [31].

The results obtained from this study reveal that technological infrastructure and resources, organization culture and, secure and accessible data warehousing can improve learning analytics impact as it was suggested by [25], [26], [28], [29], [30], [39]. However, other factors for instance, learning environment, student selfmanagement and competition from external factors should have effect on learning analytics impact which is our future research interest.

\subsection{Practical implication/suggestions}

This study may have several implications that can be divided according to the constructs proposed for better understanding of factors affecting the deployment and impact of learning analytics in developing countries and Egypt in specific.

- Organizational culture: building a culture in the university that encourages innovation and entrepreneurship along with the availability of formal rules and policies is essential to enhance learning analytics awareness and increase its impact with the availability of student-centric approach.

- University Ability: the universities in developing countries especially Egypt need to focus more on providing seminars and trainings for students on the usage of new technologies. It is also recommended to increase the money directed to the investment in new technological resources as well as recruiting learning analytics' professionals to maintain the learning analytics technology.

- Data Governance: for better learning analytics awareness, universities should inform students about the purpose of collecting their educational data, maintain the security of their data and accessibility at any time. The more the data is visualized in an understandable way, the more the students will realize the importance of learning analytics.

- Technological Infrastructure: it is essential for universities to make sure that learning analytics technology is compatible with the learning management system already in operation for smooth integration and easy implementation which leads to higher awareness. 
- Learning analytics awareness: there is a desperate need for learning analytics to be maintained in universities especially in Egypt. Students perceive it as a key element for providing them with their learning progress throughout their course work. The provision of feedback through learning analytics is important for promoting academic and professional development. This can help students at achieving better educational performance, also the universities can use it for increasing the efficiency of internal operations with better quality leading to an overall success for the higher educational institution.

\section{$6 \quad$ Limitations and future research}

This research was limited to undergraduate students from Egyptian universities with a sample mainly focused on business administration and engineering students. Accordingly, the findings should be investigated across different majors and different countries to be generalized as well as the inclusion of other learning analytics beneficiaries such as faculty members, educational decision-makers, academic advisors. Furthermore, the data collection method was solely focused on a quantitative approach; it is suggested that future research should focus on deploying a mixed method approach in an attempt to triangulate the results and find other factors that can affect the deployment of learning analytics in the context of developing countries.

\section{Conclusion}

Learning analytics has been strongly recognized in developed countries: it's time to shed light on its usage in developing countries especially Egypt. The study indicates high learning analytics awareness and high perceived impact on the Egyptian higher education institutions. The study revealed that organizational culture, data accessibility, trustworthy, visualization has a positive effect on the awareness, while lack of university ability has a negative effect on the awareness. Both infrastructure and awareness have a significant positive effect on learning analytics. This can indicate the readiness of organizational culture and data governance of the universities with a more need to excel in the resources and training for developing analytical skills within the organization.

The work presented in this study should be of great significance to the university, academics, researchers, education ministry and the educational policymakers as well because it offers a road map for universities in developing countries especially Egypt to implement and maintain a good practice of learning analytics technology. More evidence should be extracted with the collection of more insights from students, faculty members and decision makers. 


\section{$8 \quad$ References}

[1] Leitner, P., Khalil, M. and Ebner, M., 2017. Learning analytics in higher education-a literature review. In Learning analytics: Fundaments, applications, and trends (pp. 1-23). Springer, Cham. https://doi.org/10.1007/978-3-319-52977-6_1

[2] Basha, I., Hussein, A., \& Maklad, N. (2021). Distance Learning Applicability in Egyptian Construction Engineering Education. International Journal of Emerging Technologies in Learning (iJET), 16(3), 220-234. https://doi.org/10.3991/ijet.v16i03.18019

[3] Zotov, V., Ibrahim, I., Petunina, I., \& Lazareva, Y. (2021). Engagement of Students in Data Visualization for the Purpose of E-Learning Improvement. International Journal of Emerging Technologies in Learning (iJET), 16(2), 46-64. https://doi.org/10.3991/ijet.v16i0 $\underline{2.18745}$

[4] Badran, A., Baydoun, E. and Hillman, J.R. eds., 2019. Major challenges facing higher education in the Arab world: Quality assurance and relevance. Springer. https://doi.org/10.10 07/978-3-030-03774-1_1

[5] El Gamal, S. and Abd El Aziz, R., 2012. Improving higher education in Egypt through elearning programs: HE students and senior academics perspective. International Journal of Innovation in Education, 1(4), pp.335-361. https://doi.org/10.1504/ijiie.2012.052738

[6] Sclater, N., Peasgood, A. and Mullan, J., 2016. Learning analytics in higher education. London: Jisc. Accessed February, 8(2017), p.176. https://doi.org/10.4324/9781315679563

[7] Okkonen, J., Helle, T. and Lindsten, H., 2020, February. Expectation Differences Between Students and Staff of Using Learning Analytics in Finnish Universities. In International Conference on Information Technology and Systems (pp. 383-393). Springer, Cham. https://doi.org/10.1007/978-3-030-40690-5 38

[8] Wise, A.F., Zhao, Y. and Hausknecht, S.N., 2014. Learning Analytics for Online Discussions: Embedded and Extracted Approaches. Journal of Learning Analytics, 1(2), pp.4871. https://doi.org/10.18608/jla.2014.12.4

[9] Bichsel, J., 2012. Analytics in higher education: Benefits, barriers, progress, and recommendations. EDUCAUSE Center for Applied Research.

[10] Del Blanco, Á., Serrano, Á., Freire, M., Martínez-Ortiz, I. and Fernández-Manjón, B., 2013, March. E-Learning standards and learning analytics. Can data collection be improved by using standard data models?. In 2013 IEEE Global Engineering Education Conference (EDUCON) (pp. 1255-1261). https://doi.org/10.1109/educon.2013.6530268

[11] Ifenthaler, D. and Tracey, M.W., 2016. Exploring the relationship of ethics and privacy in learning analytics and design: implications for the field of educational technology. Educational Technology Research and Development, 64(5), pp.877-880. https://doi.org/10.1007/ $\underline{\text { s11423-016-9480-3 }}$

[12] Dietz-Uhler, B. and Hurn, J.E., 2013. Using learning analytics to predict (and improve) student success: A faculty perspective. Journal of interactive online learning, 12(1), pp.1726.

[13] Avella, J.T., Kebritchi, M., Nunn, S.G. and Kanai, T., 2016. Learning analytics methods, benefits, and challenges in higher education: A systematic literature review. Online Learning, 20(2), pp.13-29. https://doi.org/10.24059/olj.v20i2.790

[14] Dinu, V.E., Papuc, D., Gheorghiu, A., Dascalu, M.I., Moldoveanu, A. and Moldoveanu, F., 2017. Biometric data in learning analytics: a survey on existing applications. eLearning and Software for Education, 2.

[15] Papamitsiou, Z. and Economides, A.A., 2014. Learning analytics and educational data mining in practice: A systematic literature review of empirical evidence. Journal of Educational Technology and Society, 17(4), pp.49-64. 
[16] Banihashem, S.K., Aliabadi, K., Pourroostaei Ardakani, S., Delaver, A. and Nili Ahmadabadi, M., 2018. Learning analytics: A systematic literature review. Interdisciplinary Journal of Virtual Learning in Medical Sciences, 9(2). https://doi.org/10.5812/ijvlms.63024

[17] Guenaga, M. and Garaizar, P., 2016. From analysis to improvement: Challenges and opportunities for learning analytics. IEEE Revista Iberoamericana de Tecnologias del Aprendizaje, 11(3), pp.146-147. https://doi.org/10.1109/rita.2016.2589481

[18] Siemens, G., 2013. Learning analytics: The emergence of a discipline. American Behavioral Scientist, 57(10), pp.1380-1400. https://doi.org/10.1177/0002764213498851

[19] Willis, J.E., Slade, S. and Prinsloo, P., 2016. Ethical oversight of student data in learning analytics: a typology derived from a cross-continental, cross-institutional perspective. Educational Technology Research and Development, 64(5), pp.881-901. https://doi.org/10.10 07/s11423-016-9463-4

[20] Ifenthaler, D. and Schumacher, C., (2016). "Student perceptions of privacy principles for learning analytics". Educational Technology Research and Development, 64(5), pp.923938. https://doi.org/10.1007/s11423-016-9477-y

[21] Ferguson, R., 2012. Learning analytics: drivers, developments and challenges. International Journal of Technology Enhanced Learning, 4(5-6), pp.304-317. https://doi.org/10.1504/ ijtel.2012.051816

[22] Arnold, K.E., Lonn, S. and Pistilli, M.D., 2014, March. An exercise in institutional reflection: The learning analytics readiness instrument (LARI). In Proceedings of the fourth international conference on learning analytics and knowledge (pp. 163-167). https://doi.org/ $\underline{10.1145 / 2567574.2567621}$

[23] Oster, M., Lonn, S., Pistilli, M.D. and Brown, M.G., 2016, April. The learning analytics readiness instrument. In Proceedings of the sixth international conference on learning analytics and knowledge (pp. 173-182). https://doi.org/10.1145/2883851.2883925

[24] Scheffel, M., Drachsler, H., Toisoul, C., Ternier, S. and Specht, M., 2017, September. The proof of the pudding: examining validity and reliability of the evaluation framework for learning analytics. In European conference on technology enhanced learning (pp. 194208). Springer, Cham. https://doi.org/10.1007/978-3-319-66610-5_15

[25] Vasyakin, B.S., Ivleva, M.I., Pozharskaya, Y.L. and Shcherbakova, O.I., 2016. A Study of the Organizational Culture at a Higher Education Institution [Case Study: Plekhanov Russian University of Economics (PRUE)]. International Journal of Environmental and Science Education, 11(10), pp.11515-11528.

[26] Zhu, C. and Engels, N., 2014. Organizational culture and instructional innovations in higher education: Perceptions and reactions of teachers and students. Educational Management Administration \& Leadership, 42(1), pp.136-158. https://doi.org/10.1177/17411432134992 $\underline{53}$

[27] Ifenthaler, D. and Yau, J.Y.K., 2019. Higher education stakeholders' views on learning analytics policy recommendations for supporting study success. International Journal of Learning Analytics and Artificial Intelligence for Education: iJAI, 1(1), pp.28-42. https:// doi.org/10.3991/ijai.v1i1.10978

[28] Schmitz, M., Scheffel, M., van Limbeek, E., Bemelmans, R. and Drachsler, H., (2018). “"Make It Personal!"-Gathering Input from Stakeholders for a Learning AnalyticsSupported Learning Design Tool”. In European Conference on Technology Enhanced Learning (pp. 297-310). Springer, Cham. https://doi.org/10.1007/978-3-319-98572-5 23

[29] Whitelock- Wainwright, A., Gašević, D., Tejeiro, R., Tsai, Y.S. and Bennett, K., 2019. The student expectations of learning analytics questionnaire. Journal of Computer Assisted Learning, 35(5), pp.633-666. https://doi.org/10.1111/jcal.12366 
[30] West, D., Huijser, H., Heath, D., Lizzio, A., Toohey, D., Miles, C., Searle, B. and Bronnimann, J., 2016. Higher education teachers' experiences with learning analytics in relation to student retention. Australasian Journal of Educational Technology, 32(5). https:// doi.org/10.14742/ajet.3435

[31] Al Amoush, A.B. and Sandhu, K., 2020. Jordan Learning Analytics Management Systems Innovation (Jordanian Universities). International Journal of Innovation in the Digital Economy (IJIDE), 11(1), pp.44-59. https://doi.org/10.4018/ijide.2020010103

[32] Badran, A., Baydoun, E. and Hillman, J.R. eds., 2019. Major challenges facing higher education in the Arab world: Quality assurance and relevance. Springer. https://doi.org/10. 1007/978-3-030-03774-1

[33] Falcao, T.P., Mello, R.F., Rodrigues, R.L., Diniz, J.R.B., Tsai, Y.S. and Ga_sevi_c, D, 2020."Perceptions and expectations about learning analytics from a brazilian higher education institution",Proceedings of the Tenth International Conference on Learning Analytics and Knowledge, pp. 240-249. https://doi.org/10.1145/3375462.3375478

[34] Hilliger, I., Ortiz-Rojas, M., Pesántez-Cabrera, P., Scheihing, E., Tsai, Y.S., MuñozMerino, P.J., Broos, T., Whitelock-Wainwright, A. and Pérez-Sanagustín, M., 2020. Identifying needs for learning analytics adoption in Latin American universities: A mixedmethods approach. The Internet and Higher Education, 45, p.100726. https://doi.org/10.10 16/j.iheduc.2020.100726

[35] West, D., Tasir, Z., Luzeckyj, A., Na, K.S., Toohey, D., Abdullah, Z., Searle, B., Jumaat, N.F. and Price,R. 2018. "Learning analytics experience among academics in Australia and Malaysia: a comparison”, Australasian Journal of Educational Technology, Vol. 34 No. 3 , pp. 122-139. https://doi.org/10.14742/ajet.3836

[36] Klein, C., Lester, J., Rangwala, H. and Johri, A., 2019. Technological barriers and incentives to learning analytics adoption in higher education: insights from users. Journal of Computing in Higher Education, 31(3), pp.604-625. https://doi.org/10.1007/s12528-019$\underline{09210-5}$

[37] Al Adwan, F.E., Al Awamrah, A.F. and Al Adwan, F.E., 2018. The extent to which students have sufficient awareness of e-learning and its relation to self-studying and academic achievement. Modern Appl. Sci, 12(1). https://doi.org/10.5539/mas.v12n1p137

[38] Schumacher, C. and Ifenthaler, D., 2018, "Features students really expect from learning analytics",Computers in Human Behavior, Vol. 78, pp. 397-407. https://doi.org/10.1016/j. chb.2017.06.030

[39] Aparicio, M., Bacao, F. and Oliveira, T., 2016. Cultural impacts on e-learning systems' success. The Internet and Higher Education, 31, pp.58-70. https://doi.org/10.1016/j.iheduc. 2016.06.003

[40] Taherdoost, H., 2016. Sampling methods in research methodology; how to choose a sampling technique for research. How to Choose a Sampling Technique for Research (April 10, 2016). https://doi.org/10.2139/ssrn.3205035

[41] Ringle, C. M., Wende, S., and Becker, J.-M. 2015. "SmartPLS 3." Boenningstedt: SmartPLS GmbH, http://www.smartpls.com.]

[42] Anderson, J. C., \& Gerbing, D. W. (1988). Structural equation modeling in practice: A review and recommended two-step approach. Psychological Bulletin, 103(3), 411-423. https://doi.org/10.1037/0033-2909.103.3.411

[43] Chin, W. W., Marcolin, B. L., \& Newsted, P. R. (2003). A partial least squares latent variable modeling approach for measuring interaction effects: Results from a Monte Carlo simulation study and an electronic-mail emotion/adoption study. Information Systems Research, 14(2), 189-217. https://doi.org/10.1287/isre.14.2.189.16018 
[44] Dubey, R., Gunasekaran, A., Childe, S.J., Roubaud, D., Wamba, S.F., Giannakis, M. and Foropon, C., 2019. Big data analytics and organizational culture as complements to swift trust and collaborative performance in the humanitarian supply chain. International Journal of Production Economics, 210, pp.120-136. https://doi.org/10.1016/j.ijpe.2019.01.023

[45] Fernando, E., Murad, D.F., Warnars, H.L.H.S. and Oktriono, K., 2019, November. Development Conceptual Model and Validation Instrument for E-Learning Succes Model at Universities in Indonesia: Perspectives influence of Instructor's Activities and Motivation. In 2019 International Congress on Applied Information Technology (AIT) (pp. 1-6). IEEE. https://doi.org/10.1109/ait49014.2019.9144754

[46] Nunnally, J. C. (1978). Psychometric theory (2nd ed.). New York: McGraw-Hill.

[47] Hair, J. F., Hult, G. T. M., Ringle, C., \& Sarstedt, M. (2013). A primer on partial least squares structural equation modelling (PLS-SEM). Los Angeles: Sage Publications.

[48] Fornell, C., \& Larcker, D. (1981). Structural equation models with unobservable variables and measurement error. Journal of Marketing Research, 18(1), 39-50. https://doi.org/10.11 77/002224378101800104

[49] Chin, W. W. (1998). The partial least squares approach for structural equation modelling. In G. A. Marcoulides (Ed.), Modern methods for business research (pp. 295-336). London: Lawrence Erlbaum Associates.

[50] Henseler, J., Hubona, G. and Ray, P.A. (2016), "Using PLS path modeling in new technology research: updated guidelines", Industrial Management \& Data Systems, Vol. 116 No. 1, pp. 2-20. https://doi.org/10.1108/IMDS-09-2015-0382

[51] David Garson, G. (2016). Partial Least Squares: Regression \& Structural Equation Models. Statistical Publishing Associates.

[52] Pavlou, P. A., Liang, H. G., \& Xue, Y. J. (2007). Understanding and mitigating uncertainty in online exchange relationships: A principal-agent perspective. MIS Quarterly, 31(1), 105-136. https://doi.org/10.2307/25148783

[53] Chin, W. W., \& Newsted, P. R. (1999). Structural equation modeling analysis with small samples using partial least squares. In R. H. Hoyle (Ed.), Statistical strategies for small sample research (pp. 307-342). Thousand Oaks, CA: Sage.

[54] Hair, J. F., Ringle, C. M., \& Sarstedt, S. (2011). PLS-SEM: Indeed a silver bullet. Journal of Marketing Theory and Practice, 19(2), 139-151. https://doi.org/10.2753/mtp1069-6679 190202

[55] Cohen, J. (1988). Statistical power analysis for the behavioral sciences (2nd ed.). Hillsdale, NJ: Erlbaum.

\section{Authors}

Mai Mahmoud is an Associate Lecturer a Business Information Systems Department, Arab Academy for Science, Technology and Maritime Transport, Alexandria, Egypt. She is currently enrolled as a PhD student at Computer Science, School of Science and Technology, Middlesex University, London, UK.

Prof. Dr. Georgios Dafoulas is a Professor of Information Systems and Business Computing in the Faculty of Science and Technology at Middlesex University, London, UK. He is the Director of Programmes Computer Science | Programme Leader BSc Business Information Systems Computer Science Department - Faculty of Science \& Technology at Middlesex University, UK (Email: G.Dafoulas@mdx.ac.uk). 
Prof. Dr. Rasha Abd ElAziz is a Professor and the Head of Business Information Systems Department at the College of Management and Technology, Arab Academy for Science and Technology, Alexandria, Egypt (Email: rasha_a@aast.edu).

Dr.Noha Saleeb is an Associate Professor in creative technologies \& construction at the Department of Design Engineering and Mathematics, Faculty of Science and Technology, Middlesex University, London, UK (Email: N.Saleeb@mdx.ac.uk).

Article submitted 2021-05-31. Resubmitted 2021-11-09. Final acceptance 2021-11-08. Final version published as submitted by the authors.

\section{Appendix A: Survey items, loadings}

\begin{tabular}{|c|c|c|c|}
\hline Construct name & Survey Item & Indicator & Loading \\
\hline \multirow{9}{*}{$\begin{array}{l}\text { Organizational } \\
\text { Culture }\end{array}$} & I believe that - my university is result-oriented. & Q12_1 & 0.573 \\
\hline & I believe that - my university cares about students. & Q12_2 & 0.705 \\
\hline & $\begin{array}{l}\text { I believe that - my university can be approached for help in } \\
\text { time of need by students }\end{array}$ & Q12_3 & 0.732 \\
\hline & I believe that - my university encourages innovation. & Q12_4 & 0.763 \\
\hline & I believe that - my university encourages entrepreneurship. & Q12_5 & 0.761 \\
\hline & $\begin{array}{l}\text { I believe that - my university promotes soft skills such as } \\
\text { teamwork, collaboration, decision-making and problem- } \\
\text { solving. }\end{array}$ & Q12_6 & 0.722 \\
\hline & $\begin{array}{l}\text { I believe that - my university has formal rules and official } \\
\text { policies to support its orderly development. }\end{array}$ & Q12_7 & 0.796 \\
\hline & I believe that - my university focuses on staff development. & Q12_8 & 0.679 \\
\hline & $\begin{array}{l}\text { I believe that - my university possesses unique and cutting- } \\
\text { edge technology. }\end{array}$ & Q12_10 & 0.692 \\
\hline \multirow{3}{*}{ University Ability } & $\begin{array}{l}\text { I believe that - my university provides required } \\
\text { training and seminars on new technology usage. }\end{array}$ & Q13_1 & 0.794 \\
\hline & $\begin{array}{l}\text { I believe that - my university invests in new resources (e.g. } \\
\text { analytical software's, learning management systems) in } \\
\text { order to find solutions to educational problems. }\end{array}$ & Q13_2 & 0.899 \\
\hline & $\begin{array}{l}\text { I believe that - my university has professionals who are } \\
\text { specialized in analytics tools. }\end{array}$ & Q13_5 & 0.814 \\
\hline \multirow{5}{*}{ Data Governance } & $\begin{array}{l}\text { I believe that - my university ensures that educational data is } \\
\text { kept secure. }\end{array}$ & Q14_1 & 0.746 \\
\hline & $\begin{array}{l}\text { I believe that - my university informs students before using } \\
\text { any identifiable data about them. }\end{array}$ & Q14_2 & 0.795 \\
\hline & $\begin{array}{l}\text { I believe that - in my university, it is clear what educational } \\
\text { data is being collected and for what purpose. }\end{array}$ & Q14_3 & 0.838 \\
\hline & $\begin{array}{l}\text { I believe that - in my university, educational data is accessi- } \\
\text { ble at any time. }\end{array}$ & Q14_4 & 0.794 \\
\hline & $\begin{array}{l}\text { I believe that - in my university, educational data visualiza- } \\
\text { tion is clear. }\end{array}$ & Q14_6 & 0.729 \\
\hline $\begin{array}{l}\text { Technological } \\
\text { Infrastructure }\end{array}$ & $\begin{array}{l}\text { I believe that - learning analytics are compatible with the } \\
\text { university's technological infrastructure. }\end{array}$ & Q15_1 & 0.886 \\
\hline
\end{tabular}




\begin{tabular}{|c|c|c|c|}
\hline & $\begin{array}{l}\text { I believe that - learning analytics fit well with the universi- } \\
\text { ty's existing operating practices. }\end{array}$ & Q15_2 & 0.899 \\
\hline & $\begin{array}{l}\text { I believe that - The university can integrate educational data } \\
\text { from different resources easily. }\end{array}$ & Q15_3 & 0.789 \\
\hline \multirow{5}{*}{$\begin{array}{l}\text { Learning Analyt- } \\
\text { ics Awareness }\end{array}$} & $\begin{array}{l}\text { I believe that - There is a need now for learning analytics to } \\
\text { be integrated in the educational process }\end{array}$ & Q16_1 & 0.783 \\
\hline & $\begin{array}{l}\text { I believe that - Learning analytics are essential for providing } \\
\text { students with their learning progress based on their educa- } \\
\text { tional data }\end{array}$ & Q16_2 & 0.861 \\
\hline & $\begin{array}{l}\text { I believe that - Learning analytics are essential for presenting } \\
\text { students with a complete profile of their learning across } \\
\text { every module. }\end{array}$ & Q16_3 & 0.817 \\
\hline & $\begin{array}{l}\text { I believe that - Learning analytics are essential for help } \\
\text { teaching staff in the provision of feedback and support to } \\
\text { students }\end{array}$ & Q16_4 & 0.876 \\
\hline & $\begin{array}{l}\text { I believe that - learning analytics are essential for promoting } \\
\text { academic and professional skill development. }\end{array}$ & Q16_5 & 0.835 \\
\hline \multirow{7}{*}{$\begin{array}{l}\text { Learning Analyt- } \\
\text { ics Impact }\end{array}$} & $\begin{array}{l}\text { I believe that - Learning analytics will enable me to achieve } \\
\text { tasks more quickly. }\end{array}$ & Q17_1 & 0.780 \\
\hline & $\begin{array}{l}\text { I believe that - Learning analytics will make it easier to } \\
\text { achieve tasks. }\end{array}$ & Q17_3 & 0.753 \\
\hline & I believe that - Learning analytics will be useful for my job. & Q17_4 & 0.789 \\
\hline & $\begin{array}{l}\text { I believe that - Learning analytics will help the university at } \\
\text { improving the efficiency of internal operations. }\end{array}$ & Q17_5 & 0.734 \\
\hline & $\begin{array}{l}\text { I believe that - Learning analytics will help the university } \\
\text { improve the educational process quality. }\end{array}$ & Q17_6 & 0.799 \\
\hline & $\begin{array}{l}\text { I believe that - Learning analytics improves coordination } \\
\text { within the university. }\end{array}$ & Q17_7 & 0.831 \\
\hline & $\begin{array}{l}\text { I believe that - Learning analytics will help the university to } \\
\text { achieve overall success. }\end{array}$ & Q17_8 & 0.765 \\
\hline
\end{tabular}

\section{Appendix B: Cross-loadings}

\begin{tabular}{|l|c|c|c|c|c|c|}
\hline & $\begin{array}{c}\text { Organizational } \\
\text { Culture }\end{array}$ & $\begin{array}{c}\text { University } \\
\text { Ability }\end{array}$ & $\begin{array}{c}\text { Data } \\
\text { Governance }\end{array}$ & $\begin{array}{c}\text { Technological } \\
\text { Infrastructure }\end{array}$ & $\begin{array}{c}\text { Learning Analytics } \\
\text { Awareness }\end{array}$ & $\begin{array}{c}\text { Learning Analytics } \\
\text { Impact }\end{array}$ \\
\hline Q12_1 & 0.573 & 0.146 & 0.099 & 0.152 & 0.398 & 0.299 \\
\hline Q12_2 & 0.705 & 0.622 & 0.506 & 0.568 & 0.220 & 0.326 \\
\hline Q12_3 & 0.732 & 0.574 & 0.438 & 0.464 & 0.134 & 0.212 \\
\hline Q12_4 & 0.763 & 0.648 & 0.525 & 0.519 & 0.166 & 0.246 \\
\hline Q12_5 & 0.761 & 0.596 & 0.419 & 0.456 & 0.178 & 0.256 \\
\hline Q12_6 & 0.722 & 0.639 & 0.557 & 0.502 & 0.156 & 0.220 \\
\hline Q12_7 & 0.796 & 0.467 & 0.397 & 0.372 & 0.316 & 0.422 \\
\hline Q12_8 & 0.679 & 0.621 & 0.426 & 0.621 & 0.126 & 0.258 \\
\hline Q12_1 & 0.692 & 0.708 & 0.504 & 0.540 & 0.114 & 0.233 \\
\hline Q13_1 & 0.613 & 0.794 & 0.512 & 0.594 & 0.131 & 0.269 \\
\hline Q13_2 & 0.622 & 0.899 & 0.574 & 0.651 & 0.204 & 0.231 \\
\hline Q13_5 & 0.536 & 0.814 & 0.562 & 0.580 & 0.162 & 0.251 \\
\hline
\end{tabular}


Paper-Factors Affecting the Deployment of Learning Analytics in Developing Countries: Case of Egypt

\begin{tabular}{|l|l|l|l|l|l|l|}
\hline Q14_1 & 0.427 & 0.525 & 0.746 & 0.614 & 0.300 & 0.305 \\
\hline Q14_2 & 0.354 & 0.458 & 0.795 & 0.519 & 0.276 & 0.264 \\
\hline Q14_3 & 0.458 & 0.534 & 0.838 & 0.561 & 0.303 & 0.323 \\
\hline Q14_4 & 0.434 & 0.495 & 0.794 & 0.490 & 0.330 & 0.285 \\
\hline Q14_6 & 0.482 & 0.586 & 0.729 & 0.583 & 0.192 & 0.265 \\
\hline Q15_1 & 0.511 & 0.650 & 0.677 & 0.886 & 0.271 & 0.336 \\
\hline Q15_2 & 0.500 & 0.615 & 0.596 & 0.899 & 0.345 & 0.359 \\
\hline Q15_3 & 0.523 & 0.617 & 0.530 & 0.789 & 0.264 & 0.260 \\
\hline Q16_1 & 0.310 & 0.198 & 0.284 & 0.258 & 0.783 & 0.557 \\
\hline Q16_2 & 0.327 & 0.206 & 0.324 & 0.323 & 0.861 & 0.566 \\
\hline Q16_3 & 0.239 & 0.070 & 0.221 & 0.241 & 0.817 & 0.515 \\
\hline Q16_4 & 0.255 & 0.148 & 0.335 & 0.309 & 0.876 & 0.617 \\
\hline Q16_5 & 0.299 & 0.212 & 0.352 & 0.296 & 0.835 & 0.645 \\
\hline Q17_1 & 0.359 & 0.252 & 0.327 & 0.301 & 0.535 & 0.780 \\
\hline Q17_3 & 0.287 & 0.220 & 0.224 & 0.306 & 0.494 & 0.753 \\
\hline Q17_4 & 0.274 & 0.244 & 0.265 & 0.260 & 0.565 & 0.789 \\
\hline Q17_5 & 0.446 & 0.383 & 0.411 & 0.405 & 0.496 & 0.734 \\
\hline Q17_6 & 0.307 & 0.175 & 0.198 & 0.259 & 0.544 & 0.799 \\
\hline Q17_7 & 0.349 & 0.209 & 0.275 & 0.249 & 0.570 & 0.831 \\
\hline Q17_8 & 0.268 & 0.131 & 0.318 & 0.274 & 0.593 & 0.765 \\
\hline
\end{tabular}

